$\underline{\text { Avicenna Journal of Nursing and Midwifery Care - ISSN 2676-5748 }}$

\title{
Effect of Healing Program on Quality of Life in Chemotherapy Patients
}

\author{
Banafshe Samari $^{1}$, Eisa Mohammadi ${ }^{*}$, Fazlollah Ahmadi ${ }^{1}$ \\ 1. Department of Nursing, Faculty of Medical Sciences, Tarbiat Modares University, Tehran, Iran
}

\begin{tabular}{|c|c|}
\hline Article Info & ABSTRACT \\
\hline $\begin{array}{l}\text { Received: 2018/12/30; } \\
\text { Accepted: 2019/01/8; } \\
\text { Published Online: 2019/03/27 }\end{array}$ & $\begin{array}{l}\text { Introduction: Cancer and tolerance of severe therapies affect all aspects of life } \\
\text { and generally the quality of life of patients. Spiritual care is one of the most important } \\
\text { types of care for cancer patients. The most important element in spiritual care is } \\
\text { healing. The aim of this study was to determine the effect of healing program on } \\
\text { quality of life in chemotherapy patients }\end{array}$ \\
\hline
\end{tabular}

Methods: This study is a semi experimental study in two private hospitals in

10.30699/sjhnmf.27.4.222

Original Article

Use your device to scan and read the article online

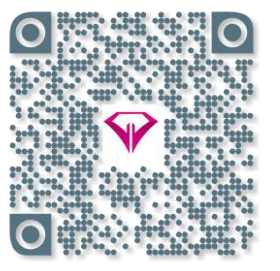
Tehran in 20017. The samples were first selected from among the patients who were referred to two hospitals. Quality of life of patients before and after two months after intervention was measured and recorded by a specific questionnaire for measuring the quality of life of cancer patients. For analyzing, descriptive and analytic tests such as mean differences test and analysis of variance were used using SPSS 20. Data was analyzed using SPSS 21 software, t-paired and t-independent test.

Results: Chi-square and analysis of variance showed that the two groups had no significant difference in terms of demographic characteristics, effective variables, and mean of quality of life in terms of dimensions and in general. And the mean of quality of life of the patients in the intervention group was significantly higher than the control group two months after the intervention $(\mathrm{P}<0.05)$.

Conclusion: Healing attendance alone as an integral part of spiritual care can be effective in improving the quality of life of patients. Therefore, nurses can advise that their care will be more effective if they focus on their presence along with patients in caring activities and focus on indicators and elements designed to heal.

Keywords: Healing presence, Spiritual care, Quality of life, Chemotherapy patients

Corresponding Information: $\quad$ Eisa Mohammadi, Department of Nursing, Faculty of Medical Sciences, Tarbiat Modares University, Tehran, Iran. Email:mohamade@modares.ac.ir

Copyright $($ C 2019, This is an original open-access article distributed under the terms of the Creative Commons Attribution-noncommercial 4.0 International License which permits copy and redistribution of the material just in noncommercial usages with proper citation.

\section{How to Cite This Article:}

Samari B, Mohammadi E, Ahmadi F. Effect of Healing Program on Quality of Life in Chemotherapy Patients . Avicenna J Nurs Midwifery care. 2019; 27 (4) 


\section{تعيين تأثير برنامهٔ مراقبتى مبتنى بر حضور التيام بخش بر كيفيت زندگى بيماران شيمىدرمانى بنفشه ثمرى'، عيسى محمدى'"، فضلاله احمدى'} ا. تروه برستارى، دانشكدة علومبزشكى، دانشعاه تربيتمدرس، تهران، /يران

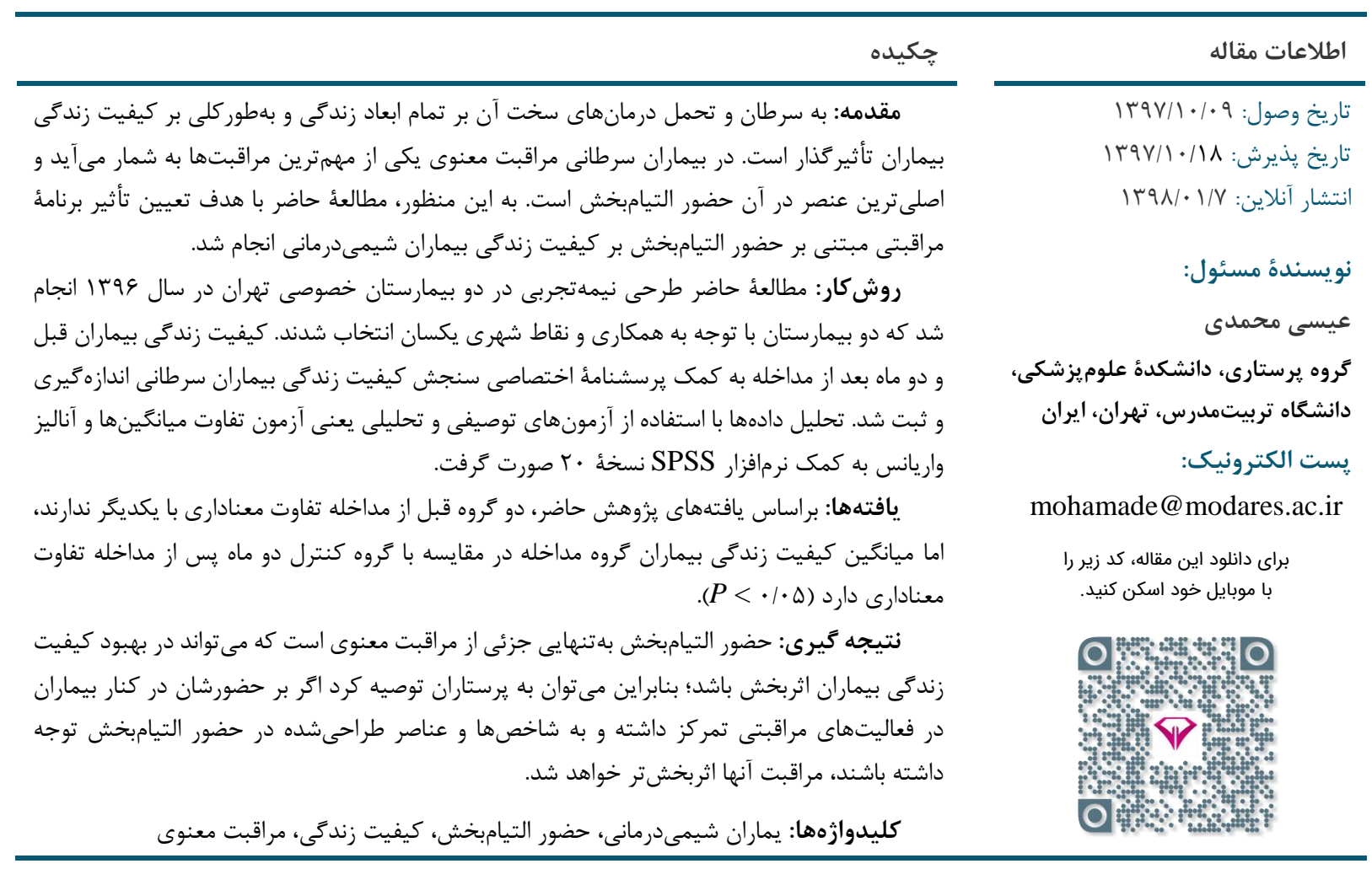

مقدمه

ناشى از آن، بر وضعيت جسمى، عملكردى و روانى اجتماعى

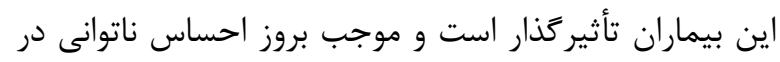

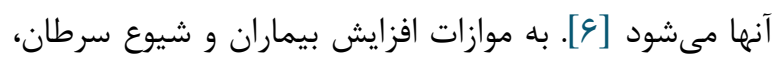

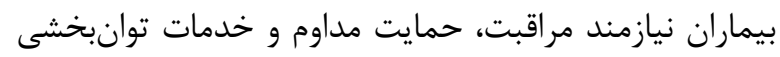

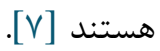

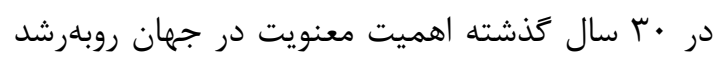
بوده است. اين امر در حرفئ يرستارى نيز به رسميت شناخته

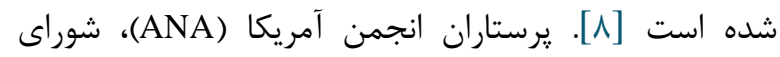

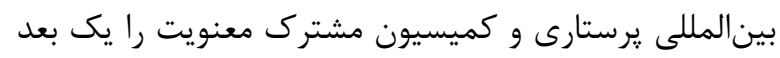

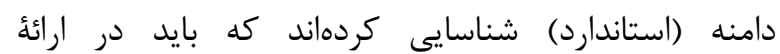
مر اقبتهاى بهداشتى محترم شمرده شود [9]. مراقبت معنوى

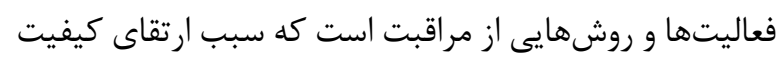
زندگى معنوى، سلامت معنوى و عملكرد معنوى مى معود. مراقبت معنوى بر پاسخ فرد به استرس، سلامت معنوى تعادل
سرطان يكى از بيمارىهاى روبهرشد است [1]. 9 درصد

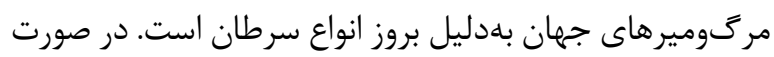

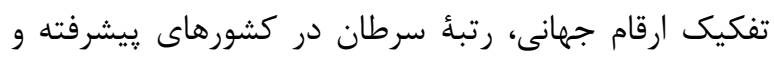
روبهيشرفت در حال تغيير است. در كشورهاى پيشرفته،

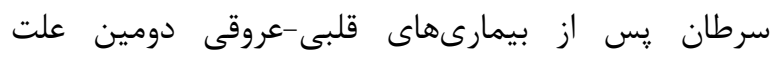

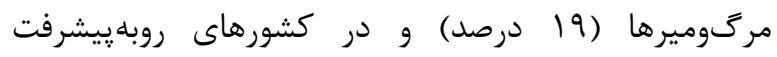

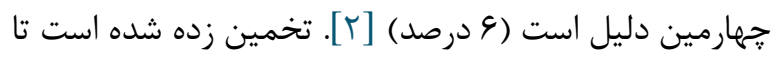

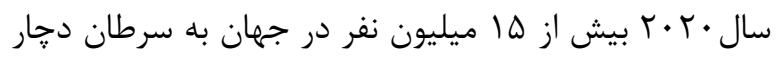

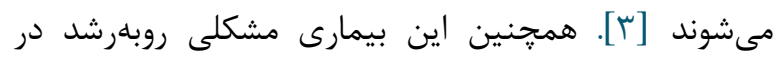

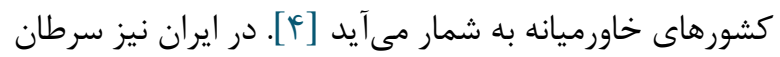
سومين عامل مرى بعد از بيمارىهاى قلبى و تصادفهاست.

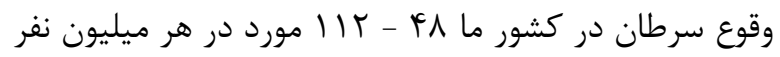

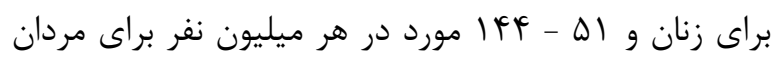
است [Q]. ابتلا به سرطان، تحمل درمانهاى سخت و خستخى 
دوستداشتن آنها در آن موقعيت مثالهايى مرتبط با حضور است. حضور راهى براى بودن با كسى در آن شرايط است؛

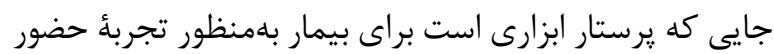

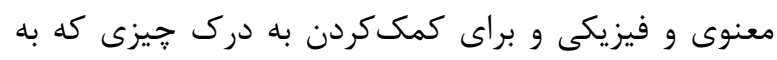

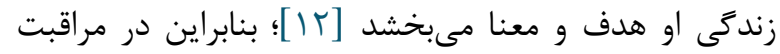

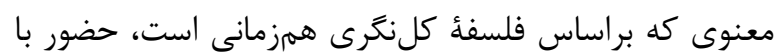
قيد التيامبخش مفهومسازى مىشود. در اين زمينه، مطالعات كَوناگونى وجود دارد. Shafipour

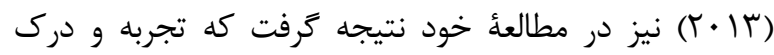

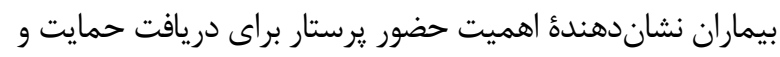

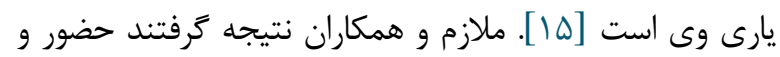

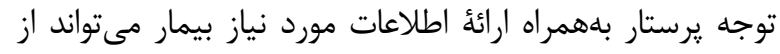

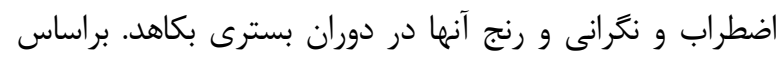

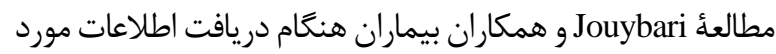

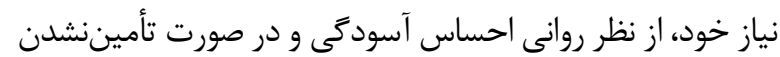
اين نيازها احساس نآرامى مى كنند [19.

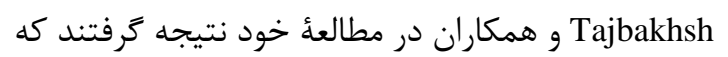
مراقبت معنوى-مذهبى، تأثير معنى دارى در كاهش استرس مط دارد

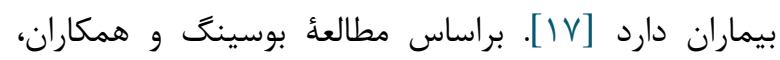

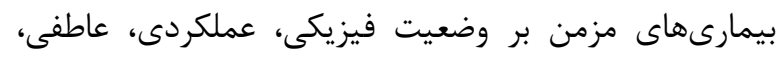

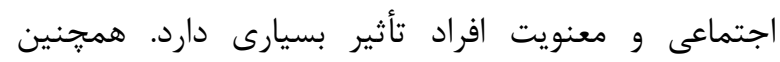

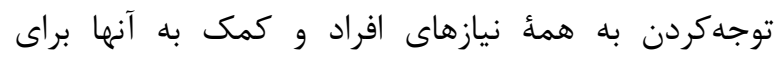

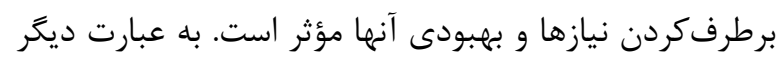

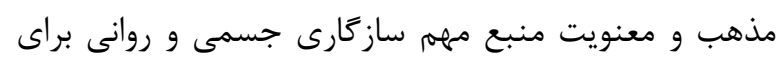

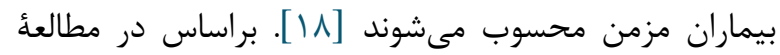

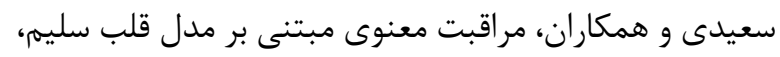

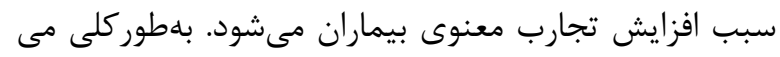

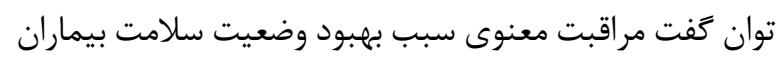

$$
\text { مىشود [19]. }
$$

در مطالعات گَوناگون بر مراقبت معنوى تأكيد شده است،

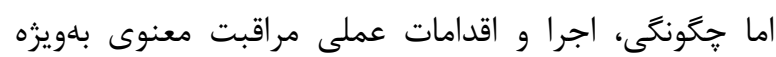
حضور التيامبخش بهطور جزئى و عملياتى بيان نشده و واتئ

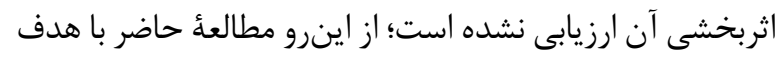

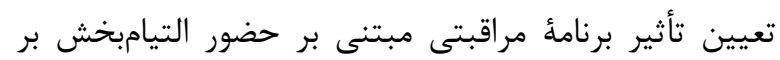
كيفيت زندگى بيماران شيمى درمانى انجام شد.

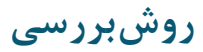

ميان جوانب جسمى، روانى، اجتماعى و معنوى احساس

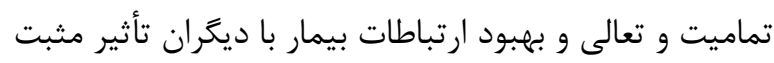

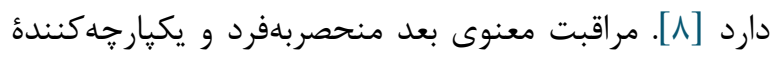

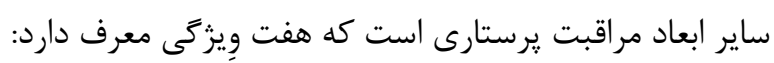
حضور التيامبخش، استفادة درمانى از خود، درى شهرودى،

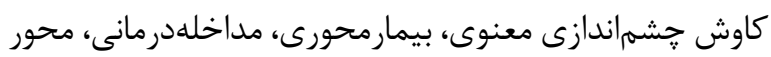

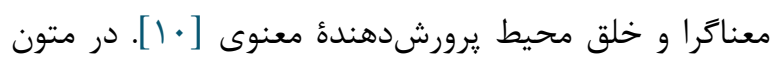

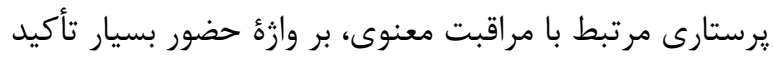

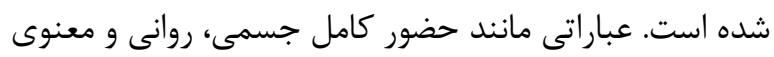

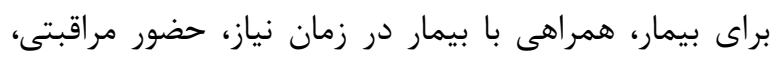

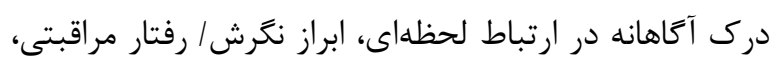

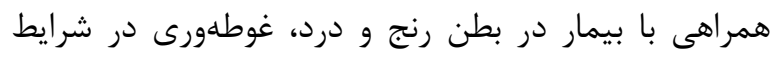

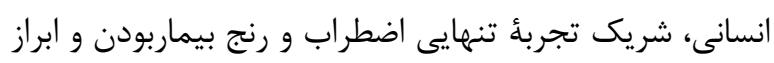

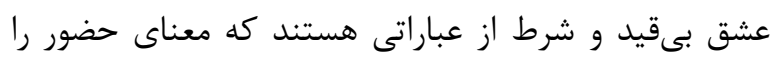

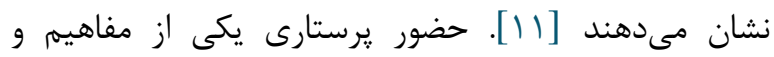

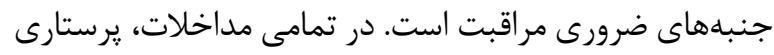

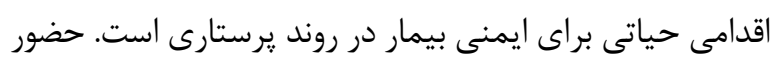

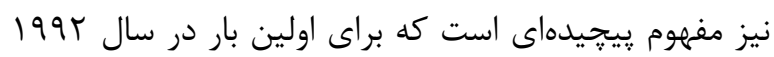

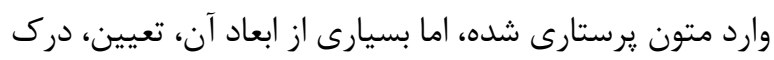

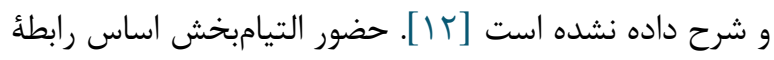

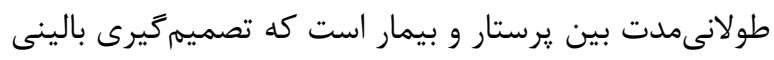

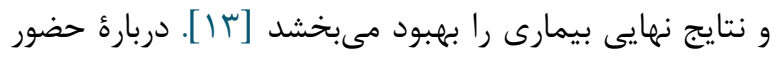

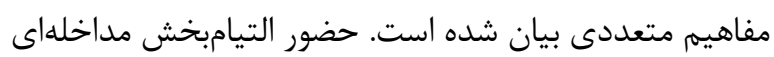

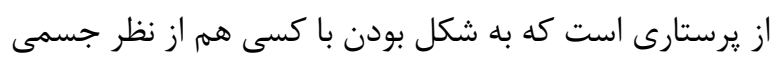

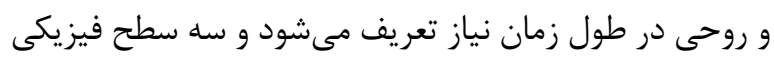

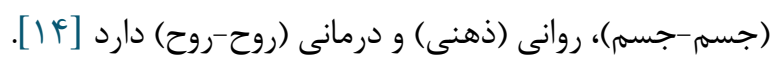

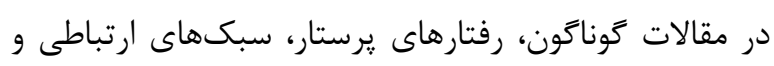

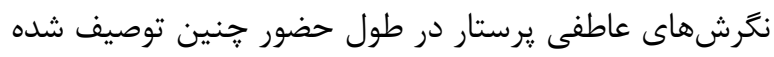

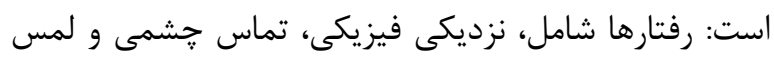

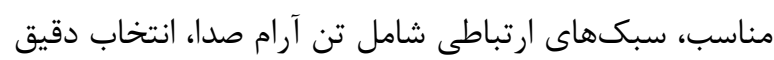

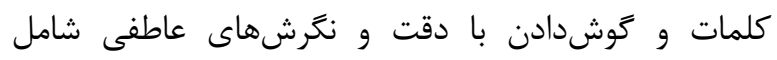

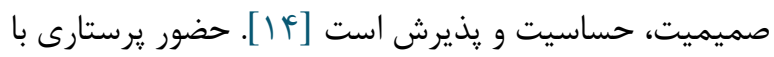

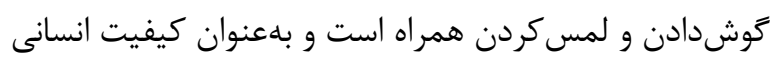

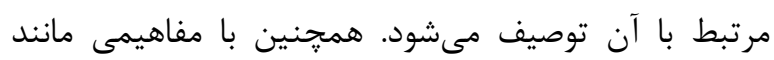

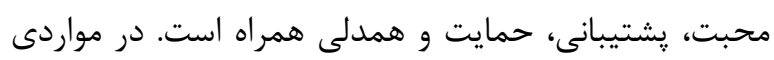

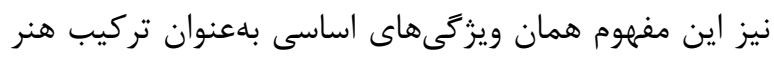

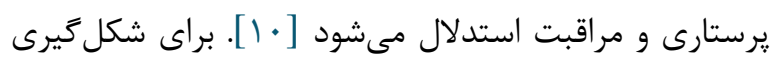
حضور در لحظات سخت، سكوت، نشاندادن احترام و 


$$
n=\frac{(1.96+0.84)^{2}\left((7.9)^{2}+(7.6)^{2}\right)}{(37.33-40.76)^{2}}=75.61 \cong 76
$$

مع از كسب مجوز لازم براى يروهش در جامعهُ مدنظر از

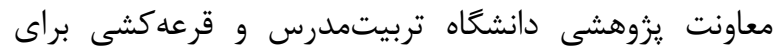

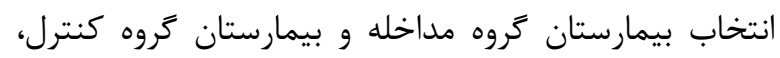

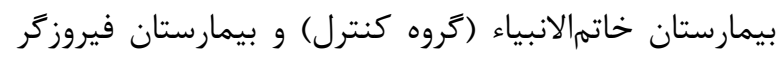
بخش مراقبت تسكينى (كروه مداخله) كه مديريت آن مستقل

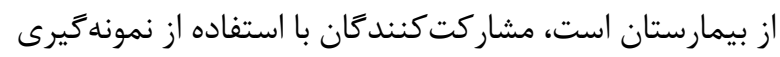

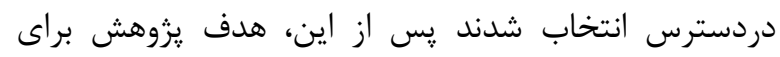
شركتكنندكان در يروهش تشريح و اطمينان داده شد كه آندان

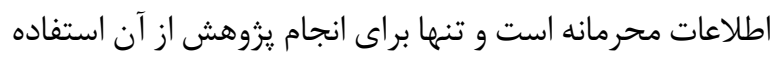

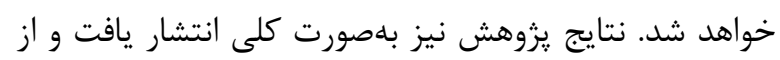
شركت كنندكان در يزوهش رضايتنامة كتبى كرفته شد. در ابتدا، يزوهشكر مطالعات و منابع مرتبط با مراقبت رضات

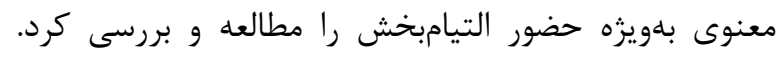
براساس بررسى و جمعبندى اين منابع، حضور التيامبخش إنش شش بعد دارد كه عبارت است از: ارتباط با تجربئ بيمار، حضور

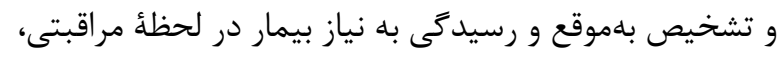

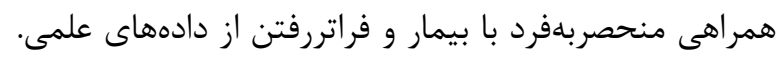

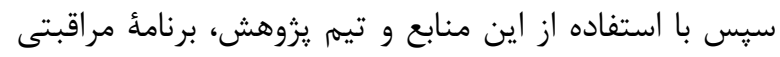
مبتنى بر حضور التيامبخش براى بيماران شيمىدرمانى إنى

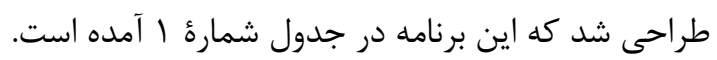

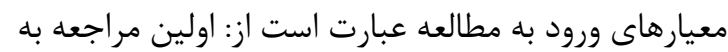
بيمارستان مدنظر براى انجام شيمىدرمانى، سن بيشتر از هأل،

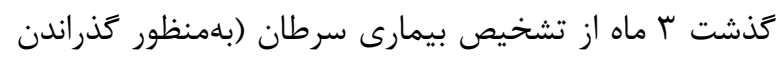

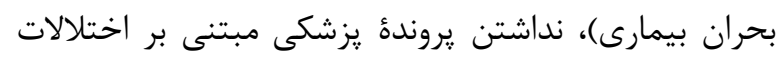

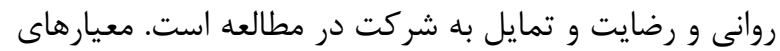

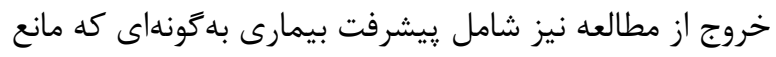

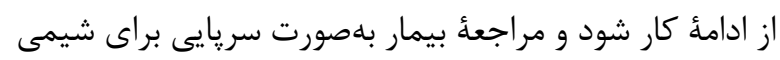
درمانى (بسترىشدن مجدد، يا بسترى در بخش تنها به مدت

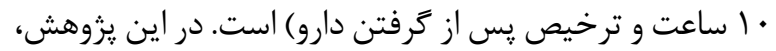

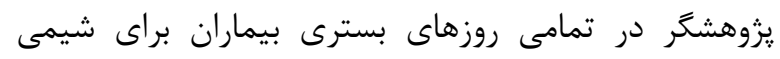

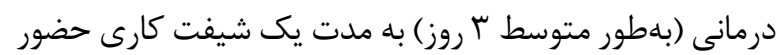
داشت و برنامةٔ حضور التيامبخش را براى آنان اجرا كرد. هنغام

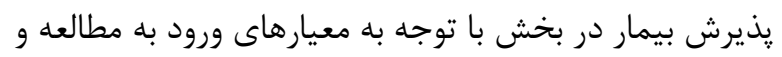

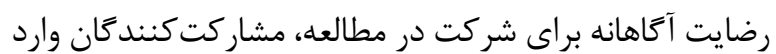

يزوهش حاضر نيمهتجربى است كه در دو گروه (كنترل و

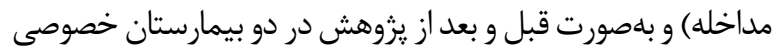

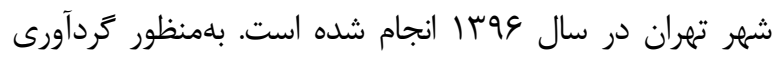
دادهها از يرسشنامهٔ دموكرافيك و يرسشنامة اختصاصى سنجش كيفيت زندگى در مبتلايان به سرطان (EORTC) استفاده شد. اين

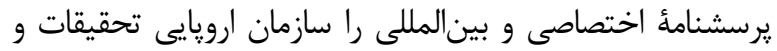

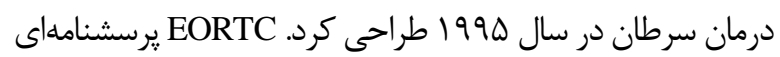

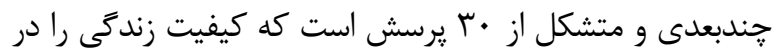
ينج حيطؤ عملكردى (جسمانى، ايفاى نقش، احساسى، شناختى و

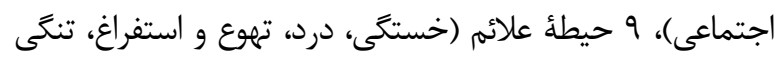
نفس، اسهال، يبوست، كاهش خواب، كاهش اشتها و مشكلات

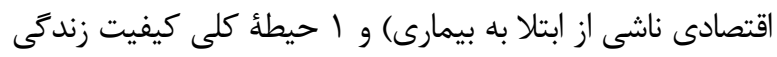

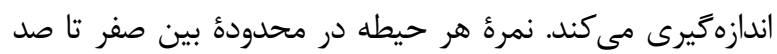

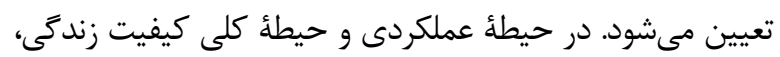
نمره بالاتر نشانكر وضعيت بهتر عملكرد يا كيفيت زندكى استى

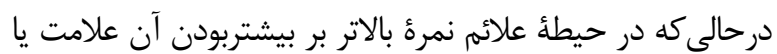
مشكل دلالت دارد [· [ب]. اين يرسشنامه از تعدادى يرسشهاى كمى تشكيل شده است تا حتى بيمارانى كه توانايى جسمى كمى دارند، بتوانند

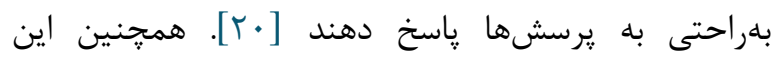

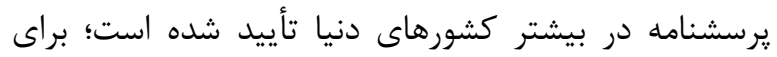

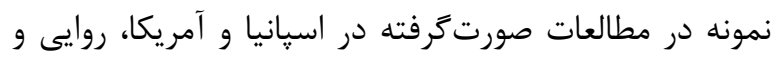

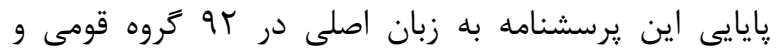

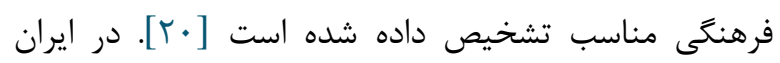
نيز Safaee و همكاران اين يرسشنامه را ترجمه و وِايايى و

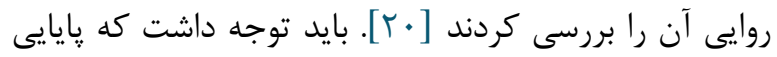

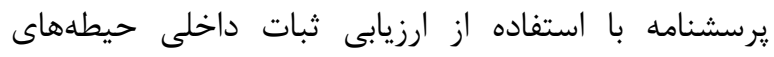
جنديرسشى تعيين شده است. در يروهش حاضر نيز بهمنظور سنجش روايى ابزار، ابتدا

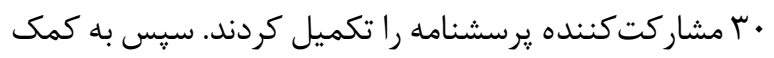

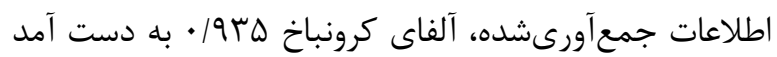
كه مقدار يذيرفتهاى است. با توجه به فرمول زير و يافته إناى

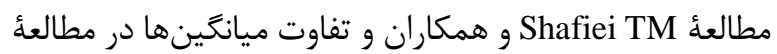

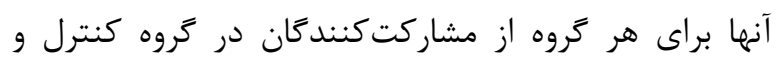
مداخله V Vفر تعيين شد. $n=\frac{\left(z_{1-\alpha / 2}+z_{1-\beta}\right)^{2}\left(S_{1}^{2}+S_{2}^{2}\right)}{\left(\bar{x}_{1}-\bar{x}_{2}\right)^{2}}$ 
دادههاى يزوهش نيز با استفاده از SPSS نسخئ عا، آمار

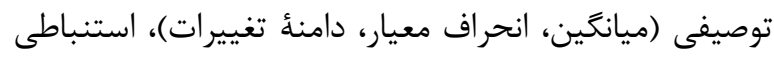

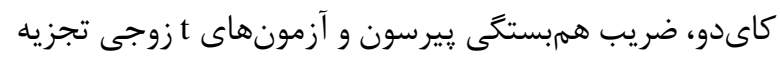

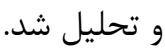

يزوهش، در هر زمان در صورت تمايلنداشتن به ادامٔ مطالعه رعايت شد.

تحليل دادهاى يزوهش در نرمافزار SPSS نسخه صورت كرفت. بهمنظور بررسى توزيع نرمال دادهایى كمى از

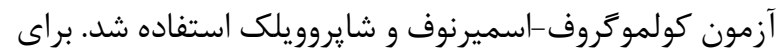

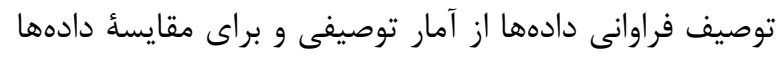

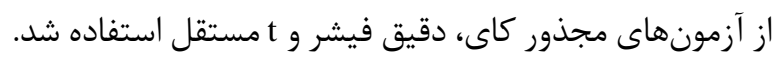

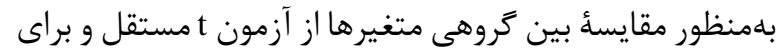

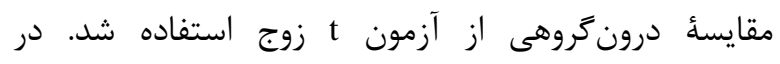

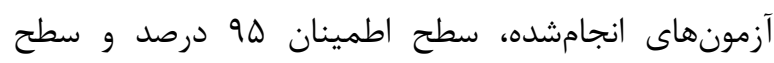
معنادارى ه ه/

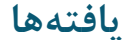

براساس يافتههاى يزوهش، توزيع نمونهها در دو كروه كنترل

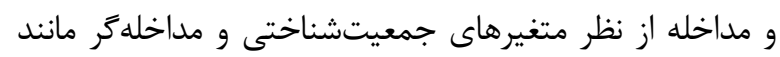

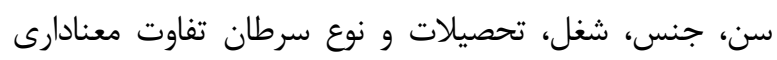

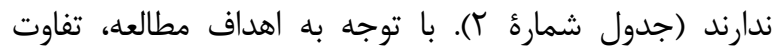
معنادارى در نتايج براى قبل و بعد از مداخله در كروه كنترل

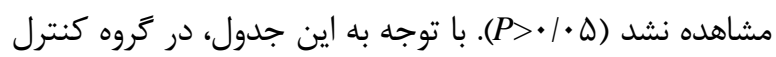
كه از برنامةٔ مراقبتى حضور التيامبخش استفاده نشده بود، تغييرى در ابعاد كيفيت زندگى، عملكردى و علائم مشاهده نشد (جدول

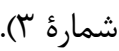
براساس نتايج آزمون t زوجى، در كروه آزمون قبل و بعد از

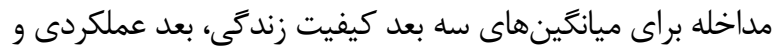

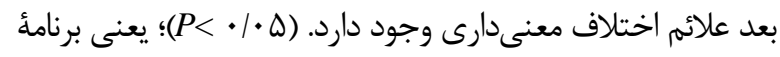

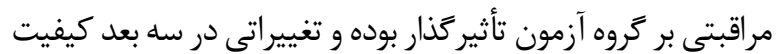

زندگى، عملكردى و علائم ايجاد كرده است. (جدول شمارئ ع).

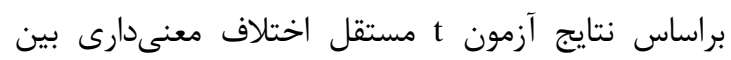

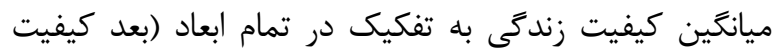

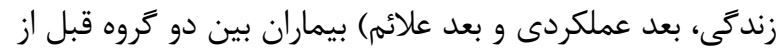

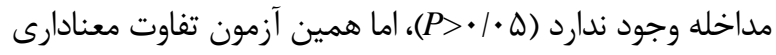

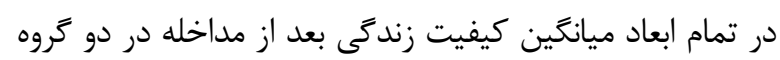

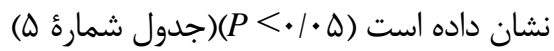

يزوهش شدند و يرسشنامئ دموكرافيك و يرسشنامة سنجش اختصاصى كيفيت زندگى در اختيار آنان قرار كرفت. سيس

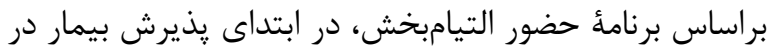

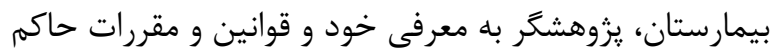
بر بخش (آشنايى با بخش و قوانين بخش و كاركنان بخش

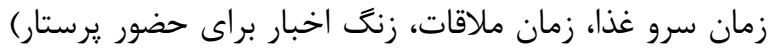

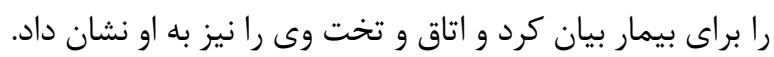
سيس با حضور منظم بر بالين بيمار، نيازهاى او را برطرف كرد.

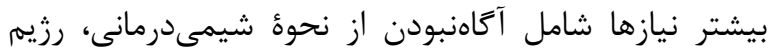

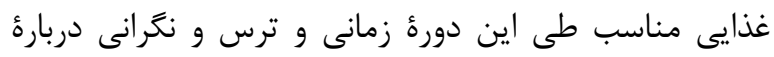
بيمارى سرطان بود؛ از اينرو براى برطرفكردن اين اين نيازها

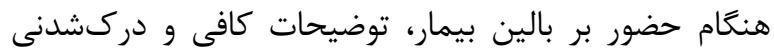

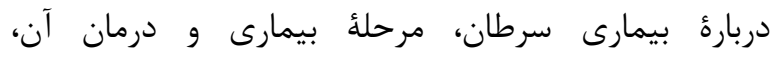
شيمىدرمانى، عوارض شيمىدرمانى، رزيم غذايى و كنترل عوارض شيمىدرمانى به بيمار داده شد. علاوه بر اين، يمفلتهاى آموزشى حاوى تمامى اطلاعات آموزش در اختيار

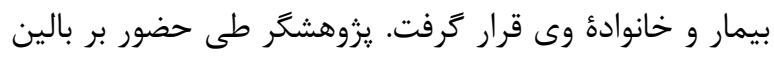
بيمار، همل صحبتهاى او را شنيده و براى تمامى رويههاى مراقبتى زمان كافى و مناسب در نظر كرفته است. همجنين در همأ مراحل، با مهربانى و خوش روريى با بيمار رفتار كرده و در در تمامى لحظات كه بيمار احساس غم و اندوه و ناراحتى كرده با با بـا شريكشدن در عواطف و احساسات درونى بيمار، همجنين حمايتهاى روحى و روانى در كنار او قرار كرفته است و با رفتار كلامى و غير كلامى عشق و علاقهٔ خود را به بيمار نشان دادي داده

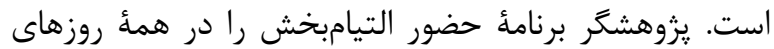
بسترى بيماران به مدت يك شيفت كارى (^ ساعت در روز)

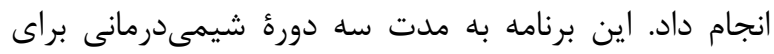

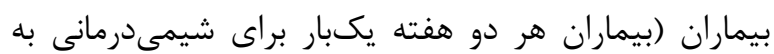

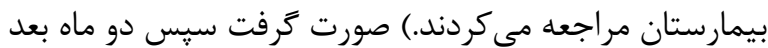
از اولين برنامهٔ حضور التيامبخش بيماران كه براى ادامدئ

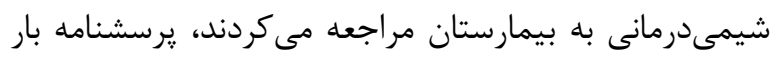

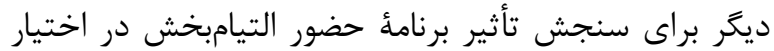

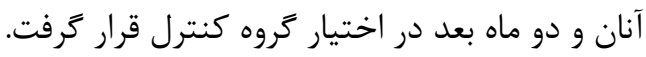
با توجه به معيارهاى ورود به مطالعه و دريافت رضايت آكاهانه از مشاركت كنندكان كه براى شيمى بردمانى به به

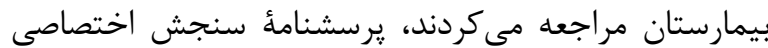

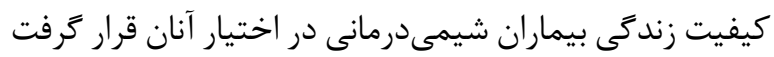

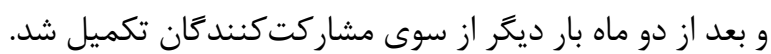


جدول ا. برنامهٔ عملياتى تعريف و طراحىشده براساس ويثَّى هاى حضور التيامبخش

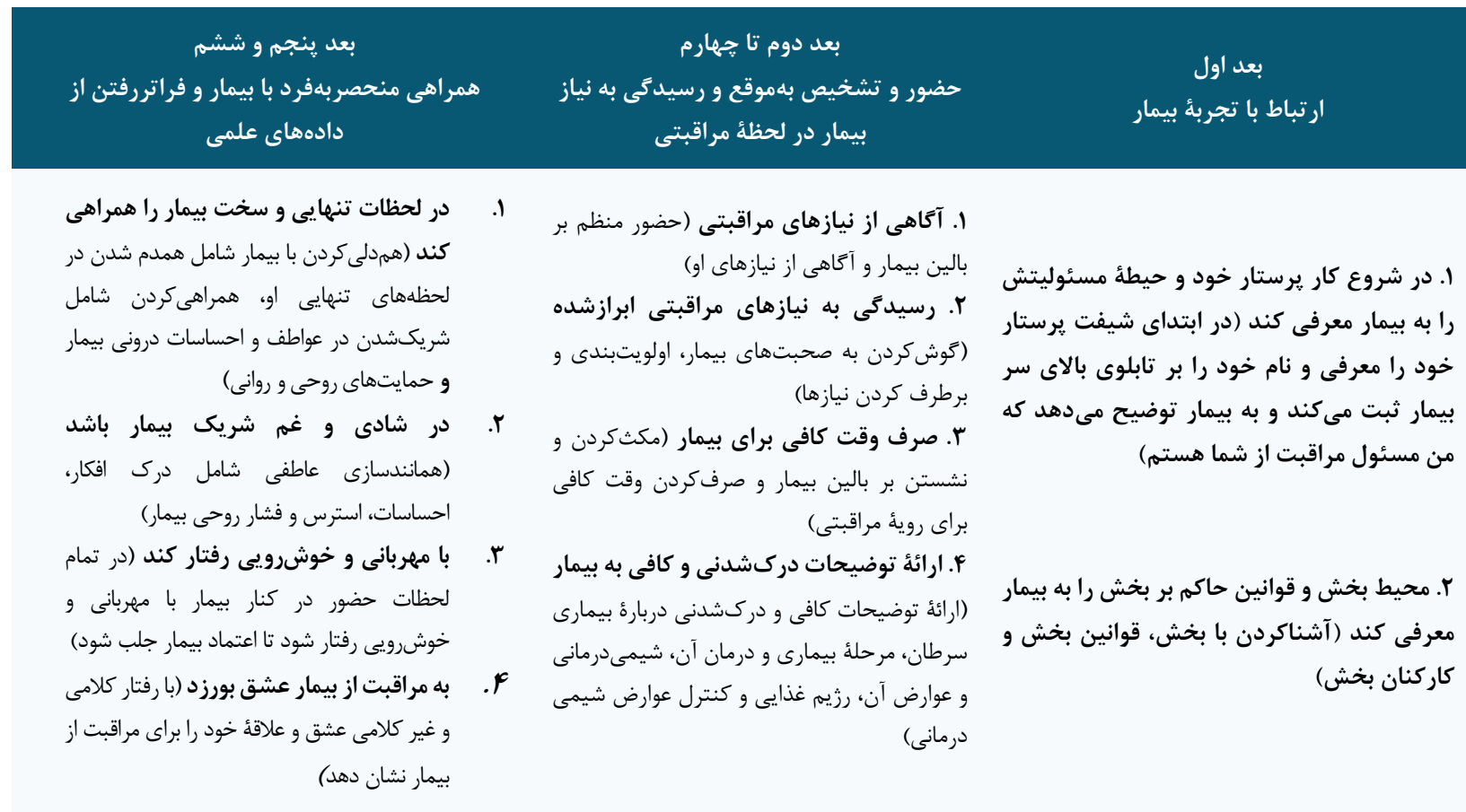

جدول r. مشخصات دموكر افيك مشاركت كنندكًان

\begin{tabular}{|c|c|c|c|c|c|c|}
\hline$P$ value & تروه آزمون & تعداد & تروه كنترل & تعداد & \multicolumn{2}{|c|}{ مشخصات } \\
\hline \multirow{2}{*}{$\cdot / N^{c}$} & ع/\& ه درصد & r. & . ه درصد & r & مرد & \multirow{2}{*}{ جنس } \\
\hline & F & קצr & مه مدرصد & r & زن & \\
\hline \multirow{3}{*}{.$/ 19$} & هأ درصد & re & ع بورصد & cq & G. -10 & \multirow{3}{*}{ سن } \\
\hline & ه/Nא درصد & r & سז درصد & re & SI-VQ & \\
\hline & ه/ه درصد & r & r درصد & $r$ & vq-q. & \\
\hline \multirow{3}{*}{$\cdot / V 1$} & ج/ T درصد & rt & هז درصد & 19 & زير دييلم & \multirow{3}{*}{ تحصيلات } \\
\hline & וא וא درصد & rT & Nא & rv & دييلم & \\
\hline & qא/ درصد & rt & س/عז درصد & $r$. & بالاى دييلم & \\
\hline \multirow{5}{*}{.$/ 91$} & ז/سا درصد & 1. & ג/1ا درصد & 9 & كارمند & \multirow{5}{*}{ شغل } \\
\hline & //آ درصد & 19 & 19/V درصد & 10 & آزاد & \\
\hline & / / & $M$ & ז אTr/ درصد & iv & بازنشسته & \\
\hline & ه/r درصد & v & 1/1/ درصد & 9 & بيكار & \\
\hline & q/T درصد & ra & ז/F درصد & rq & خانهدار & \\
\hline \multirow{8}{*}{.$/ D F$} & / I זرصد & 19 & / I درصد & 19 & كولون & \multirow{8}{*}{ نوع سرطان } \\
\hline & 1/1ا درصد & 9 & 1/1| درصد & 9 & معده & \\
\hline & / 9/r درصد & v & r/ץ درصد & v & ريه & \\
\hline & ه/ r درصد & r & r/r/ درصد & 1. & مثانه & \\
\hline & 1/1/ درصد & 10 & ه/F/ا درصد & 11 & سينه & \\
\hline & 19/V درصد & 10 & ג/1/ درصد & 9 & كولور كتال & \\
\hline & V/9 درصد & 9 & V/q درصد & 9 & ر & \\
\hline & ه/ آ درصد & 11 & ه/. إدصد & $\wedge$ & خون & \\
\hline
\end{tabular}


جدول با. ميانََينهاى كيفيت زندكَى بيماران شيمىدرمانى قبل و بعد از مداخله در كروه كنترل و آزمون

\begin{tabular}{|c|c|c|c|c|c|c|}
\hline \multirow{2}{*}{ نوع آزمون } & \multirow{2}{*}{$\mathrm{P}$ value } & \multicolumn{2}{|c|}{ بعد از مداخله } & \multicolumn{2}{|c|}{ قبل از مداخله } & تروه كنترل \\
\hline & & انحراف معيار & ميانكَين & انحراف معيار & ميانكَين & \\
\hline $\begin{array}{c}\mathrm{T}=\cdot / / 9 \mathrm{f}^{\mathrm{s}} \\
\mathrm{df}=\mathrm{V} \Delta\end{array}$ & - /AFV & $1 / \Delta$. & $V / F$ & $1 / \Delta \Lambda$ & v/ra & كيفيت زندَّى \\
\hline $\begin{array}{c}\mathrm{T}=\cdot / 911 \\
\mathrm{df}=\mathrm{v} \Delta\end{array}$ & DEA & s/re & $r q / \Delta V$ & $V / T \Lambda$ & $r \cdot / F V$ & عملكردى \\
\hline $\begin{array}{l}\mathrm{T}=1 / \cdot \Delta \\
\mathrm{df}=\mathrm{v} \Delta\end{array}$ & . & ת/r & rg/At & S/VD & $r \Delta / v \gamma$ & علائم \\
\hline
\end{tabular}

جدول Fا. ميانكينهاى كيفيت زندكى بيماران شيمىدرمانى قبل و بعد از مداخله در كروه كنترل و آزمون

\begin{tabular}{|c|c|c|c|c|c|c|}
\hline $\begin{array}{l}T=r / 9 q \\
d f=v \Delta\end{array}$ & $.1 . .1$ & Var & $v / q$ & $1 / \Lambda$. & $s / v 1$ & كيفيت زندوه مداخله \\
\hline $\begin{array}{c}\mathrm{T}=\mid \varepsilon / \mathrm{Ir} \\
\mathrm{df}=\mathrm{V} \Delta\end{array}$ &.$/ . .1$ & Q/Tr & $r V / T \Delta$ & $\varepsilon / 10$ & $r \mid / \cdot r$ & عملكردى \\
\hline $\begin{array}{l}\mathrm{T}=1 r / \kappa q \\
\mathrm{df}=\mathrm{r} \Delta\end{array}$ &.$/ .1$ & $\Delta / \& \bar{C}$ & $r|s|$ & $\Delta /<q$ & $r \Delta / \mu^{c}$ & علائم \\
\hline
\end{tabular}

جدول ه. مقايسؤ ميانكين ابعاد مختلف كيفيت زندكى بيماران شيمىدرمانى قبل و بعد از مداخله در هر دو تروه آزمون و كنترل

\begin{tabular}{|c|c|c|c|c|c|c|c|}
\hline \multirow{2}{*}{$\begin{array}{c}\text { P value } \\
\text { T } \\
\text { df }\end{array}$} & \multicolumn{2}{|c|}{ بعد از مداخله } & \multirow{2}{*}{$\begin{array}{c}\text { P value } \\
\text { T } \\
\text { Df }\end{array}$} & \multicolumn{2}{|c|}{ قبل از مداخله } & \multirow{2}{*}{ تروه } & \multirow{2}{*}{ متغير ها } \\
\hline & انحر افمعيار & ميانگَين & & انحرافمعيار & ميانكَين & & \\
\hline \multirow{2}{*}{$\begin{array}{c}P=\cdot / \cdot r \varphi \\
\mathrm{T}=r / r \varphi \\
\mathrm{df}=1 \omega .\end{array}$} & $\Delta T / 1$ & $1 / 1$ & \multirow{2}{*}{$\begin{array}{l}P=. / . \varnothing \Delta \\
\mathrm{T}=-r / \kappa \mathrm{T} \\
\mathrm{df}=1 \Delta .\end{array}$} & $\Lambda \cdot / 1$ & $V I / s$ & آزمون & \multirow{2}{*}{ كيفيت زندگى } \\
\hline & $0 . / 1$ & $r \cdot / v$ & & $r \Delta / v$ & $r \Delta / v$ & كنترل & \\
\hline$P=. / . \cdot 1$ & $T r / \Delta$ & $r \omega / T r$ & \multirow{2}{*}{$\begin{array}{l}P=-\cdot ৭ \varphi \\
\mathrm{T}=\cdot 1 \Delta \cdot \Delta \\
\mathrm{df}=1 \Delta .\end{array}$} & $\mid \omega / 8$ & $. r / 4)$ & آزمون & \multirow[b]{2}{*}{ عملكردى } \\
\hline $\begin{array}{c}\mathrm{T}=-\mid \Gamma / \Lambda \mathrm{V} \\
\mathrm{df}=I \Delta .\end{array}$ & (צ/s & $\Delta V / r q$ & & $T N V$ & $e v / s$. & كنترل & \\
\hline$P=. / .+1$ & 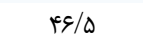 & $91 / T F$ & \multirow{2}{*}{$\begin{array}{c}P=\cdot / 4 \cdot q \\
\mathrm{~T}=-\cdot / / r q \\
\mathrm{df}=10 .\end{array}$} & $e q / \Delta$ & $\mu \kappa / \pi \Delta$ & آزمون & \multirow[b]{2}{*}{ علائم } \\
\hline 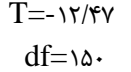 & 的 & ع & & $v \Delta / \bar{s}$ & W/ra & كنترل & \\
\hline
\end{tabular}

به دريافت عشق و مهرورزى، نياز به اميدوارى و خالقيت، نياز به بخشش، روابط صادقانه با خود، ديخران و خدا با كيفيت زندگى

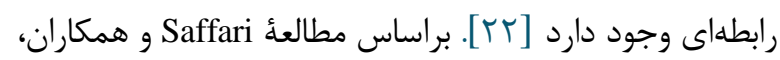
نقش باورهاى مذهبى و دينى در درمان و مقابله با بيمارىها مسئلهاى مهلم است كه بهويزه در بيمارىهايى مانند سرطان كه تهديدكنندهٔ حيات فرد است مدنظر قرار مى گيرد. تشويق بيماران و ايجاد انخيزه براى برقرارى ارتباط با خدا و باورهاى

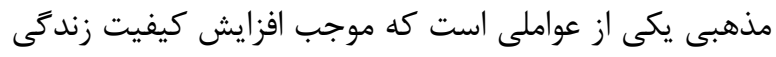

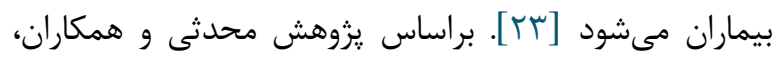

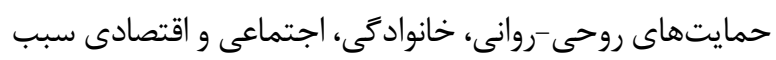

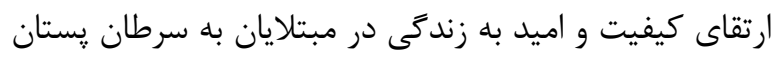

در يزوهش حاضر، تعيين تأثير برنامه مراقبتى براساس

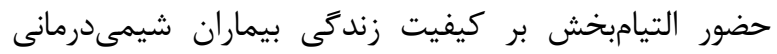

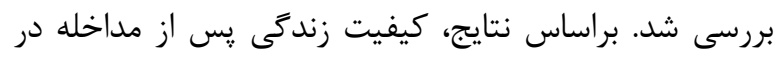

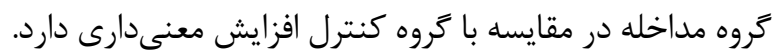
با توجه به اينكه هر دو گروه كنترل و آزمون در ويزگى مهاى جمعيتشناختى هممسان بودند، مىتوان كَفت تغييرات حاصل در ميانگين كيفيت زندگى مىتواند ناشى از برنامهٔ مراقبتى مبتنى حضور التيامبخش باشد.

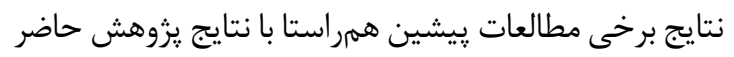

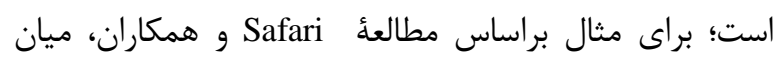
معنويت و نيازهاى آن شامل نياز به معنا و هدف در زندگى مئ، نياز 


\section{نتيجه كيرى}

براساس يافتهها و مباحث فوق، برنامٔٔ مراقبتى مبتنى بر

حضور التيامبخش سبب افزايش كيفيت زندگى بيمارانى مى مئى

كه شيمىدرمانى مىشوند؛ بنابراين كاربرد اين روش ساده، ارزان

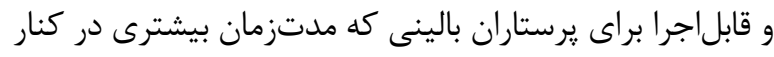

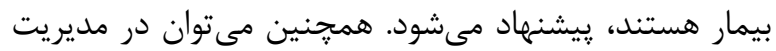

يرستارى براى صرفهجويى در زمان، هزينه، شلوغى بيمارستانها

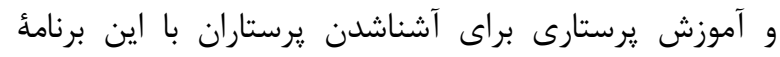

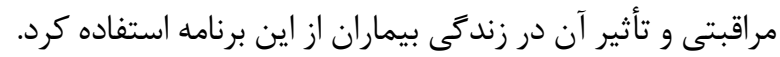

\section{سياسگَزارى}

مطالعه حاضر از يايانامئ كارشناسى ارشد يرستارى دانشكدة علوميزشكى دانشعاه تربيت مدرس استخراج شده است كه به به تأيبيد كميتهٔ اخلاق دانشخاه با شمارة IR.TMU.REC.1395.430 نيز رسيده است. آرزوى سلامتى روزافزون را براى سلامتى بيماران

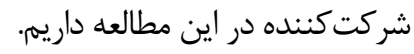

$$
\text { تعارض در منافع }
$$

بين نويسندكان هيجگ

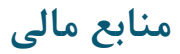

منابع مالى اين مطالعه توسط نويسندكان تامين شده است.

\section{References}

1. Jabaaij L, van den Akker M, Schellevis FG. Excess of health care use in general practice and of comorbid chronic conditions in cancer patients compared to controls. BMC family practice. 2012 Dec;13(1):60. [DOI: 10.1186/1471-2296-13-60] [PMID] [PMCID]

2. Shojaei-Tehrani H. Medical, preventive and social teaching book: prevalent chronic disease. Tehran: Samat Publications. 2004:3-5.

3. Higginson IJ, Costantini M. Dying with cancer, living well with advanced cancer. European journal of cancer. 2008 Jul 1;44(10):1414-24. [DOI:10.1016/j.ejca.2008.02.024] [PMID]

4. Daher M. Opioids for cancer pain in the Middle Eastern countries: a physician point of view. Journal of pediatric hematology/oncology. 2011 Apr 1;33:S23-8. [DOI:10.1097/MPH.0b013e3182121a0f] [PMID]
مىشود كه تحت درمانهاى مختلف جراحى، شيمىدرمانى و راديوترايى قرار دارند [بr]]. در اين يزوهش بيشترين تغيير در بعد علائم (11 درصد) مشاهده شده است؛ به عبارت ديخر، برنامهٔ مراقبتى حضور التيامبخش در حيطه علائم تفاوت بيشترى با با بـا حيطههاى عملكردى و حيطهُ كلى كيفيت زندگى دارد؛ بهطورى كه علائم بيمارى مانند تهوع، استفراغ، اختلال در اجابت مزاج و... در بيماران در مقايسه با ساير ابعاد عملكردى و كلى كيفيت زندگى مانى بهبود يافته است. آشنايى با بخش، توضيحدادن روند درمان و نوع

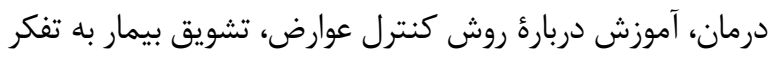
مثبت، همصحبتشدن با بيمار و گوشدادن به صحبتهاى او

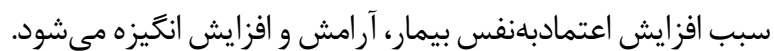
بررسى عوامل مرتبط با كيفيت زندگى در بيماران سرطانى و

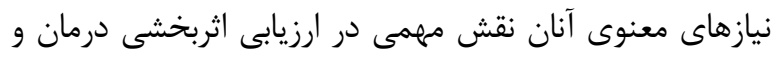
روند بيمارى دارد؛ بهطورى كه در سالهاى اخير شناسايى و رفع نيازهاى معنوى بيماران مبتلا به سرطان بهعنوان هدف مطلوب و

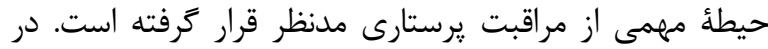
بخشى از برنامةٔ مراقبتى مبتنى بر حضور التيامبخش نيز به

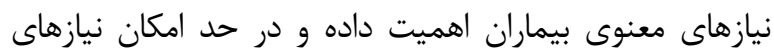

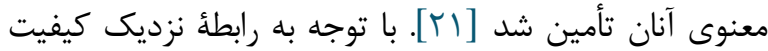
زندگى و نيازهاى معنوى، بهبود و ارتقاى عوامل مرتبط در بيماران

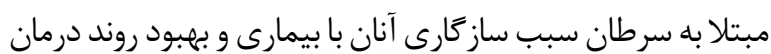
در اين بيماران مىشود [T/T]. يثوهش حاضر با محدوديتهاى زمانى و حالات روحى متفاوت مشاركت كنندگان كه بر كيفيت

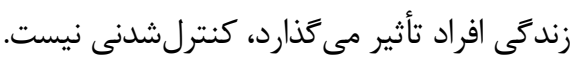

5. Mousavi SM, Pourfeizi A, Dastgiri S. Childhood cancer in Iran. Journal of pediatric hematology/oncology. 2010 Jul $1 ; 32(5): 376-82$ [DOI:10.1097/MPH.0b013e3181e003f7] [PMID]

6. Eyigor S, Akdeniz S. Is exercise ignored in palliative cancer patients? World journal of clinical oncology. 2014 Aug 10;5(3):554. [DOI:10.5306/wjco.v5.i3.554] [PMID] [PMCID]

7. Salakari MR, Surakka T, Nurminen R, Pylkkänen L. Effects of rehabilitation among patients with advances cancer: a systematic review. Acta Oncologica. 2015 May 28;54(5):618-28. [DOI:10.3109/0284186X.2014.996661] [PMID]

8. Cavendish R, Konecny L, Mitzeliotis C, Russo D, Luise BK, Medeíindt J, Bajo MA. Spiritual care activities of nurses using nursing interventions classification (NIC) labels. International Journal of Nursing Terminologies and Classifications. 2003 Oct;14(4):113-24. [DOI:10.1111/j.1744-618X.2003.00113.X] [PMID]

$$
\text { مجله مراقبت يرستارى و مامايى ابنسينا }
$$


9. Taylor EJ, Petersen C, Oyedele O, Haase J, editors. Spirituality and spiritual care of adolescents and young adults with cancer. Seminars in oncology nursing; 2015: Elsevier. [DOI:10.1016/j.soncn.2015.06.002] [PMID]

10. McMahon MA, Christopher KA. Toward a mid-range theory of nursing presence. InNursing Forum $2011 \mathrm{Apr}$ 1 (Vol. 46, No. 2, pp. 71-82). Wiley/Blackwell (10.1111). [DOI:10.1111/j.1744-6198.2011.00215.x] [PMID]

11. Ramezani M, Ahmadi F, Mohammadi E, Kazemnejad A. Spiritual care in nursing: a concept analysis. International Nursing Review. 2014 Jun;61(2):211-9. [DOI:10.1111/inr.12099] [PMID]

12. Mohammadipour F, Atashzadeh-Shoorideh F, Parvizy S, Hosseini M. Concept Development of "Nursing Presence": Application of Schwartz-Barcott and Kim's Hybrid Model. Asian nursing research. 2017 Mar 1;11(1):19-29. [DOI:10.1016/j.anr.2017.01.004] [PMID]

13. Anderson JH. The impact of using nursing presence in a community heart failure program. Journal of Cardiovascular Nursing. 2007 Mar 1;22(2):89-94. [DOI:10.1097/00005082-200703000-00002] [PMID]

14. Ross L. Spiritual care in nursing: an overview of the research to date. Journal of clinical Nursing. 2006 Jul;15(7):852-62. 2702.2006.01617.x] [PMID]

15. Shafipour V, Mohammadi E, Ahmadi F. Experiences of open heart surgery patients from admission to discharge: a qualitative study. Iran J Crit Care Nurs. 2013;6(1):1-0.

16. Jouybari L, Oskouie F, Ahmadi FA. Comfort of hospitalized patients: A missed concept. Iran Journal of Nursing. 2006 Sep;19(47):89-101.

17. Tajbakhsh F, Hosseini M, Sadeghi Ghahroudi M, Fallahi Khoshkenab M, Rokofian A, Rahgozar M. The effect of religious-spiritual care on anxiety post surgery coronary artery bypass graft patients. Iranian Journal of Rehabilitation Research in Nursing (IJRN). 2014;1(1):51-61.

18. Visser A, Garssen B, Vingerhoets A. Spirituality and well-being in cancer patients: a review. Psychooncology. 2010 Jun 1;19(6):565-72. [DOI:10.1002/pon.1626] [PMID]

19. Taheri ZS, Zandi MA, Ebadi A. The effect of spiritual care based on Ghalbe Salim Model on the sleep quality of the patients with coronary artery disease. Iran J Crit Care Nurs. 2014;7(2):92-101.

20. Safaee A, Zeighami B, Tabatabaee HR, Moghimi Dehkordi B. Quality of life and related factors in breast cancer patients under chemotherapy. Iranian Journal of Epidemiology. $2008 \quad$ Feb 15;3(3):61-6. [DOI:10.4103/0019-509X.44066] [PMID]

21. SHAFIEI TM, KHODAPANAHI MK, HEIDARI M. The effectiveness of a psycho-educational intervention in improving the quality of life of patients with breast cancer.
22. SAFARI M, AZIZI ZF, TIRGARI B, JAHANI Y. RELATIONSHIP BETWEEN QUALITY OF LIFE AND SPIRITUAL NEEDS OF CANCER PATIENTS.

23. Saffari M, Zeidi IM, Pakpour AH. Role of religious beliefs in quality of life of patients with cancer. Hakim Research Journal. 2012;15(3):243-50.

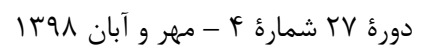

